\title{
Participant Case or Control Status
}

National Cancer Institute

\section{Source}

National Cancer Institute. Participant Case or Control Status. NCI Thesaurus. Code C99268.

An indication of a subject's status as a case or a control for a given study. 